\title{
Dual Antiplatelet Therapy After Drug-eluting Stent Implantation
}

\author{
Giulia Magnani and Marco Valgimigli \\ Bern University Hospital, Inselspital, Bern, switzerland
}

\begin{abstract}
The current guidelines for percutaneous coronary intervention use recommend dual antiplatelet therapy (DAPT) with aspirin and a P2Y12 inhibitor after drug eluting stent (DES) implantation. The optimal duration of DAPT is however area of debate. Recent clinical trials and meta-analyses suggest that the choice of DAPT duration should be tailored individually, based on the balance between ischemic and bleeding risk carried by the patient.
\end{abstract}

\section{Keywords}

Dual antiplatelet therapy, drug-eluting stent, myocardial infarction, stent thrombosis, tailored therapy

Disclosure: GM has received grants from AstraZeneca, during the conduct of the PEGASUS TIMI-54 study. MV has received fees for serving on advisory boards from AstraZeneca and St. Jude Medical; lecture fees from AstraZeneca, The Medicines Company, Terumo Medical Corporation, St. Jude Medical, Alvimedica, Abbott Vascular and Correvio; travel support from The Medicines Company; and grant support from The Medicines Company and Terumo Medical during the conduction of the MATRIX study. Received: 30 November 2015 Accepted: 17 February 2016 Citation: Interventional Cardiology Review, 2016;11(1):51-3 DOI: 10.15420/icr.2015:17:2 Correspondence: Marco Valgimigli, MD, PhD, Bern University Hospital - Inselspital, Department of Cardiology, Freiburgstrasse 4, 3010 Bern, Switzerland E: marco.valgimigli@insel.ch

Dual antiplatelet therapy (DAPT), defined as the use of a P2Y12 receptor inhibitor (clopidogrel, ticagrelor or prasugrel) and aspirin, is required after percutaneous coronary intervention ( $\mathrm{PCl}$ ) with drugeluting stents (DES). ${ }^{1}$ Although the use of DES has been shown to reduce the rate of restenosis as compared with bare-metal stents (BMS), there is concern that DES may be associated with a higher risk of late and very late stent thrombosis (ST), ,,3 particularly after DAPT discontinuation. ${ }^{4}$ DAPT prevents thrombotic complications through a double mechanism. First, DAPT protects the stented segment from ST, which occurs as a result of inflammation during healing. ${ }^{5,6}$ Second, DAPT confers protection from atherothrombotic events occurring outside the stented segment, lowering the risk of recurrent Ml., The current American College of Cardiology Foundation/American Heart Association Task Force on Practice Guidelines/Society for Cardiovascular Angiography and Interventions (ACCF/AHA/SCAI) guidelines on $\mathrm{PCl}$ use recommend at least 12 months of DAPT after DES implantation. ${ }^{8}$ The European Society of Cardiology (ESC) guidelines endorse 6-12 months of DAPT after DES implantation, ${ }^{1}$ and the ESC and the European Association for Cardio-Thoracic Surgery (ESC/EACTS) recommend 12 months for all patients with acute coronary syndrome (ACS) irrespective of revascularisation strategy. ${ }^{9}$ However, the optimal duration of DAPT post-DES implantation remains poorly defined.

The most recent clinical trials (see Table 1) and meta-analyses in patients who underwent a $\mathrm{PCl}$ with stent implantation, have highlighted two key concepts: first, the hazard rate for ischaemic events is not increased with reduced ( $<12$ months) compared with standard (12 months) or prolonged (>12 months) DAPT duration, especially with newer-generation $\mathrm{DES}^{10-12}$ and second, prolonged DAPT reduces the rate of ischaemic events at the cost of increased risk of bleeding. ${ }^{4,13}$

\section{Studies Evaluating Reduced Duration of Dual Antiplatelet Therapy}

In the Prolonging Dual Antiplatelet Treatment After Grading StentInduced Intimal Hyperplasia Study (PRODIGY) trial, consisting of a population predominantly presenting with unstable coronary artery disease, the use of DAPT for 24 months in patients who had received DES (75\%) was not significantly more effective than a 6-month clopidogrel regimen followed by aspirin monotherapy in reducing the risk of Ml or cardiac death. ${ }^{10}$ However, 24 months of clopidogrel therapy resulted in a significant increase in the number of bleeding episodes, including life-threatening events. In the Safety And Efficacy of 6 Months Dual Antiplatelet Therapy After Drug-Eluting Stenting (ISAR-SAFE) trial, 6 months of DAPT were related to similar net clinical outcome compared with 12 months of DAPT after PCI with a DES. ${ }^{14}$ Due to a slow enrolment and low event rates, the trial was stopped prematurely after enrolment of 4,005 of the 6,000 planned.

The safety of a reduced DAPT duration compared with 12-month DAPT was confirmed in a meta-analysis of 10 randomised clinical trials $(n=32,287)$, where reduced DAPT duration regimen after $\mathrm{PCI}$ with DES was associated with a significant reduction in the rate of major bleeding with no significant differences in ischaemic or thrombotic outcomes. ${ }^{15}$ On the contrary, prolonged DAPT duration reduced the incidence of thrombotic complications, including ST and MI, at the cost of increased rates of major bleeding.

The Zotarolimus-eluting Endeavor Sprint Stent in Uncertain DES Candidates (ZEUS) trial was the first to show that zotarolimus-eluting stent implantation followed by a reduced DAPT duration (median duration of 32 days) resulted in a lower risk of major cardiovascular events, compared with BMS, in a selected population of patients with stable coronary artery disease (SCAD) or ACS at high bleeding 


\begin{tabular}{|c|c|c|c|c|}
\hline Trial & $\mathbf{N}$ & $\begin{array}{l}\text { Time at randomisation } \\
\text { (months after index } \mathrm{PCl} \text { ) }\end{array}$ & DAPT regimens (months) & Primary endpoint \\
\hline ISAR-SAFE ${ }^{14}$ & 4,005 & 6 & 6 versus 12 & $\begin{array}{l}\text { Composite of death MI, ST, stroke or TIMI major bleeding at } \\
15 \text { months after } \mathrm{PCl}\end{array}$ \\
\hline PRODIGY10 & $2,013(75 \% \mathrm{DES})$ & 1 & 6 versus 24 & Composite of death, MI or CVA at 24 months after $\mathrm{PCl}$ \\
\hline $\mathrm{DAPT}^{4}$ & 9,961 & 12 & 12 versus 30 & $\begin{array}{l}\text { Definite/probable ST and MACCE defined as composite of death, } \\
\text { MI or stroke at } 30 \text { months after PCI }\end{array}$ \\
\hline OPTIDUAL ${ }^{19}$ & 1,385 & 12 & 12 versus 48 & $\begin{array}{l}\text { Composite of death, MI, stroke or major ISTH bleeding at } \\
48 \text { months after } \mathrm{PCl}\end{array}$ \\
\hline
\end{tabular}

CVA = cerebrovascular accident; DAPT = dual antiplatelet therapy; DES = drug-eluting stent; ISTH = International Society on Thrombosis and Haemostasis;

$M A C C E=$ major adverse cardiac and cerebrovascular events; $\mathrm{PCl}=$ percutaneous coronary intervention; $S T=$ stent thrombosis; $T I M I=$ thrombolysis in myocardial infarction.

or thrombosis risk or at low risk of restenosis. ${ }^{16}$ Lastly, the recent Prospective Randomized Comparison of the BioFreedom Biolimus A9 Drug-Coated Stent versus the Gazelle Bare-Metal Stent in Patients at High Bleeding Risk (LEADERS FREE) trial, involving patients at high bleeding risk who underwent $\mathrm{PCl}$ and were treated with a reduced (1-month) DAPT duration, showed that a drug-coated stent (polymerand carrier-free biolimus A9-coated stent) was superior to BMS with respect to the primary safety (composite of cardiac death, MI and ST) and efficacy (clinically driven target-lesion revascularisation) endpoints. ${ }^{17}$

\section{Studies Evaluating Prolonged Duration of Dual Antiplatelet Therapy}

The DAPT trial explored the effect of prolonged (30 months) versus 12-month DAPT (clopidogrel or prasugrel) duration in patients with ACS or SCAD at low risk of ischaemic and bleeding events and undergoing stent implantation. ${ }^{4}$ After first- or second-generation DES implantation, prolonged DAPT significantly reduce the risk of ST, cerebrovascular events and major adverse cardiovascular events. confirming a general secondary prevention effect of DAPT, much of the benefit shown in the prolonged DAPT group came from a reduction in the rate of $\mathrm{MI}$ unrelated to ST. Of particular interest, it was found that overall the rate of ischaemic events increased during the 3-month period after P2Y12 inhibition discontinuation, regardless of when that occurred. ${ }^{4}$ These data are confirmed by observations from the Prevention of Cardiovascular Events in Patients with Prior Heart Attack Using Ticagrelor Compared to Placebo on a Background of Aspirin-Thrombolysis In Myocardial Infarction (PEGASUS-TIMI 54) trial, in which patients with previous MI (39\% with previous DES implantation), enrolled after recent P2Y12 inhibitor withdrawal, were shown to be at increased risk of ischaemic events. This group derived greater benefit in terms of ischaemic risk reduction, from prolonged ticagrelor therapy plus aspirin compared with patients who had remained event-free on aspirin alone. ${ }^{13}$

Prolonged ticagrelor therapy has also been shown to reduce the rate of major cardiovascular events in patients with a history of $\mathrm{MI}$, regardless of stenting history and stent type, as well as the risk of ST in patients with stents..$^{18}$ In the DAPT ${ }^{4}$ and the PEGASUS-TIMI $54^{13}$ trials, the benefit in the reduced risk of ischaemic events was accompanied by an increase of Global Use of Strategies to Open Occluded Arteries (GUSTO)-defined moderate/severe bleeding and TIMI major bleeding, respectively. Furthermore, in the DAPT trial a higher mortality rate was observed in patients treated with prolonged DAPT compared with placebo. ${ }^{4}$ The increased non-cardiac mortality rate with extended DAPT is of uncertain significance and may be explained by an imbalance in the number of patients with cancer diagnosed before the enrolment, reflected in the higher incidence of cancer-related death observed in the prolonged-DAPT group. Consistent with the findings from the DAPT trial on ischaemic outcomes, a post-hoc analysis from the Optimal Dual Antiplatelet Therapy (OPTIDUAL) trial, showed that in patients at low risk of bleeding who underwent DES implantation, there was a trend toward fewer ischaemic events in the group randomised to prolonged (up to 48 months) DAPT therapy with clopidogrel, compared with those who stopped clopidogrel at 12 months, without increased risk of major bleeding. ${ }^{19}$

\section{Balancing the Risks of Bleeding and Ischaemic Events}

Overall, these observations suggest that a 12-month DAPT period does not represent the optimal duration for all patients undergoing a DES implantation, and that the evaluation of DAPT duration should be tailored individually, considering both the bleeding and ischaemic events risk profiles of the patient. ${ }^{15}$ Individuals at low ischaemic risk, such as patients without ACS who are undergoing $\mathrm{PCl}$, particularly if at high bleeding risk, may be suitable for shortened periods of DAPT, whereas prolonged DAPT (>12 months) could be of more benefit for selected patients without significant bleeding risk or at high ischemic risk, such as patients with previous Ml, particularly if presenting with additional cardiovascular risk factors or recurrent ischaemic events. The risk stratification is therefore a crucial step in the decision making regarding DAPT duration. Recently, the DAPT risk score has been presented; this is the first risk score with the advantage of simultaneously assessing both the bleeding and ischaemic risk, thus identifying patients who are likely to derive harm or benefit from prolonged DAPT. ${ }^{20}$ However, this score was demonstrated in a population free of major bleeding or ischaemic events in the 12-month period of DAPT and should also be validated in other datasets.

\section{Conclusion}

To further help clinicians in balancing ischaemic and bleeding risks it is necessary to carry out additional studies, as well as exploring secondary analyses of the most recent trials, to individualise the subgroups of patients that derive the greatest benefit from DAPT prolongation. Until then, clinicians should follow a personalised approach, with an ongoing risk-benefit assessment, rather than a standardised approach. 
1. Authors/Task Force members, Windecker $S$, Kolh $P$, Alfonso $F$ et al. 2014 ESC/EACTS Guidelines on myocardia revascularization: the Task Force on Myocardial Revascularization of the European Society of Cardiology (ESC) and the European Association for Cardio-Thoracic Surgery (EACTS) developed with the special contribution of the European Association of Percutaneous Cardiovascular Interventions (EAPCI). Eur Heart J 2014;35:2541-619. doi: 10.1093/eurheartj/ehu278; PMID: 25173339.

2. Eisenstein EL, Anstrom KJ, Kong DF, et al. Clopidogrel use and long term clinical outcomes after drug-eluting stent
implantation. JAMA 2007:297:159-68. PMID: 17148711

3. Valgimigli M, Campo G, Gambetti S, et al. Three-year follow-up of the MULTIcentre evaluation of Single high-dose Bolus TiRofiban versus Abciximab with Sirolimus-eluting STEnt or Bare-Metal Stent in Acute Myocardial Infarction StudY (MULTISTRATEGY). Int I Cardiol 2013;165:134-41. doi: 10.1016/j. ijcard.2011.07.106; PMID: 21864917.

4. Mauri L, Kereiakes DJ, Yeh RW, et al. Twelve or 30 months of dual antiplatelet therapy after drug-eluting stents. N Eng/ J Med 2014;371:2155-66. doi: 10.1056/NEJMoa1409312 PMID: 25399658.

5. Schomig A, Neumann FJ, Kastrati A, et al. A randomized comparison of antiplatelet and anticoagulant therapy after the placement of coronary-artery stents. $N$ Eng/ J Med 1996;334:1084-89. PMID: 8598866.

6. Leon MB, Baim DS, Popma JJ, et al. A clinical trial comparing three antithrombotic-drug regimens after coronary-artery stenting. Stent Anticoagulation Restenosis Study Investigators. N Eng/ J Med 1998:339:1665-71 PMID: 9834303

7. Yusuf S, Zhao F, Mehta SR, et al. Effects of clopidogre in addition to aspirin in patients with acute coronary syndromes without ST-segment elevation. N Eng/ I Med
2001:345:494-502 PMID: 11519503

8. Levine GN, Bates ER, Blankenship JC, et al. Guideline for Percutaneous Coronary Intervention: executive summary: a report of the American College of Cardiology Foundation/ American Heart Association Task Force on Practice Guidelines and the Society for Cardiovascular Angiography and Interventions. I Am Coll Cardiol 2011;58:e44-e122. doi:10.1016/j.jacc.2011.08.007

9. Authors/Task Force Members, Roffi M, Patrono C, Collet JP, et al. 2015 ESC Guidelines for the management of acute coronary syndromes in patients presenting without persistent ST-segment elevation: Task Force for the Management of ST-segment elovation: Task Force for the Management of Acute Coronay Syndromes in Patients Presenting without Persistent ST-Segment Elevation of the European Society of Cardiology (ESC). Eur Heart J 2016;37:267-315. doi: 10.1093/ eurheartj/ehv320; PMID: 26320110.

10. Valgimigli M, Campo G, Monti M, et al. Short- versus long-term duration of dual-antiplatelet therapy after coronary stenting: a randomized multicenter trial. Circulation 2012;125:2015-26. doi: 10.1161/CIRCULATIONAHA. 111.071589; PMID: 22438530.s

11. Colombo A, Chieffo A, Frasheri A et al Second-generation drug-eluting stent implantation followed by 6 - versus 12-month dual antiplatelet therapy: the SECURITY randomized clinical trial. J Am Coll Cardiol 2014;64:2086-97. doi: 10.1016/j. jacc.2014.09.008; PMID: 25236346

12. Cassese S, Byrne RA, Tada T, et al. Clinical impact of extended dual antiplatelet therapy after percutaneous coronary interventions in the drug-eluting stent era: A meta-analysis of randomized trials. Eur Heart 1 2012;33:3078-87. doi: 10.1093/eurheartj/ehs318; PMID: 23091199.

13. Bonaca MP, Bhatt DL, Cohen M, et al. Long-term use of ticagrelor in patients with prior myocardial infarction. $N$ Eng/ J
Med 2015:372:1791-800 doi: 10.1056/NEJMoa1500857: PMID: 25773268

14. Fiedler KA, Maeng M, Mehilli J, et al. ISAR-SAFE: randomized, double-blind, placebo-controlled trial of 6 vs. 12 months of clopidogrel therapy after drug-eluting stenting. SAR-SAFE: a randomized, double-blind, placebo-controlled trial of 6 vs. 12 months of clopidogrel therapy after drugeluting stenting. Eur Heart J 2015;36:1252-63. doi: 10.1093/ eurheartj/ehu523; PMID: 25616646

15. Navarese EP, Andreotti F, Schulze V, et al. Optimal duration of dual antiplatelet therapy after percutaneous coronary intervention with drug eluting stents: meta-analysis of randomised controlled trials. BMI 2015:350:h1618 doi: 10.1136/bmi.h1618; PMID: 25883067.

16. Valgimigli M, Patialiakas A, Thury A, et al. Zotarolimus-eluting versus bare-metal stents in uncertain drug-eluting stent candidates. J Am Coll Cardiol 2015;65:805-15. doi: 10.1016/j. jacc.2014.11.053; PMID: 25720624

17. Urban P, Meredith IT, Abizaid A, et al. Polymer-free drugcoated coronary stents in patients at high bleeding risk $\mathrm{N}$ Eng/ J Med 2015;373:2038-47. doi: 10.1056/NEJMoa1503943; PMID: 26466021.

18. Bonaca MP, Bhatt DL, Steg PG, et al. TCT-78 efficacy of longterm ticagrelor in stented patients in PEGASUS-TIMI 54. I Am Coll Cardiol 2015;66(Suppl 15). doi:10.1016/j.jacc.2015.08.121. 19. Helft G, Steg PG, Le Feuvre, et al. Stopping or continuing clopidogrel 12 months

20. after drug-eluting stent placement: the OPTIDUAL randomized trial. Eur Heart J 2016;37:365-74. doi: 10.1093/ eurheartj/ehv481; PMID: 26364288

21. Yeh RW. Individualizing treatment duration of dual antiplatelet therapy after percutaneous coronary intervention: an analysis from the DAPT Study. Abstract 20297, LBCT 3.American Heart Association 2015 